Article

\title{
Preparation of Molecularly Imprinted Mesoporous Materials for Highly Enhancing Adsorption Performance of Cytochrome C
}

\author{
Zhiling Li ${ }^{1}$, Ping Guan ${ }^{1, *}$, Xiaoling $\mathrm{Hu}^{1}$, Shichao Ding ${ }^{1}$, Yuan Tian ${ }^{1}$, Yarong $\mathrm{Xu}^{1}$ and \\ Liwei Qian ${ }^{2, *}$ \\ 1 Key Laboratory of Space Applied Physics and Chemistry of Ministry of Education, Department of Applied \\ Chemistry, School of Nature and Applied Science, Northwestern Polytechnical University, Xi'an 710072, \\ China; lizhiling1993@mail.nwpu.edu.cn (Z.L.); hux1@nwpu.edu.cn (X.H.); dingshichao1992@163.com (S.D.); \\ summer940324@163.com (Y.T.); xuyarong@mail.nwpu.edu.cn (Y.X.) \\ 2 College of Bioresources Chemical and Materials Engineering, Shaanxi University of Science and Technology, \\ Xi'an 710021, China \\ * Correspondence: guanping1113@nwpu.edu.cn (P.G.); qianliwei@mail.nwpu.edu.cn (L.Q.); \\ Tel.: +86-029-8843-1664 (P.G.); +86-029-8669-0006 (L.Q.)
}

Received: 15 February 2018; Accepted: 9 March 2018; Published: 10 March 2018

\begin{abstract}
Molecularly imprinted mesoporous materials (MIMs) were synthesized to improve the adsorption performance of Cytochrome c (Cyt c) by using an imidazolium-based amphiphilic ionic liquid 1-octadecyl-3-methylimidazolium chloride $\left(\mathrm{C}_{18} \mathrm{MIMCl}\right)$ as surfactant in aqueous solution via the epitope imprinting approach. The surface-exposed C-terminus nonapeptide of Cyt c (residues 96-104, AYLKKATNE) was utilized as the imprinted template. The nitrogen adsorption-desorption, thermo-gravimetric analysis, and transmission electron microscopy verified the successful preparation of MIMs with ordered mesoporous structure. The adsorption isotherm studies showed that the obtained MIMs exhibited superior adsorption capacity toward Cyt $\mathrm{c}$ of $86.47 \mathrm{mg} \cdot \mathrm{g}^{-1}$ because of the high specific surface areas of $824 \mathrm{~m}^{2} \cdot \mathrm{g}^{-1}$, and the appropriate pore size promoted the mass transfer of Cyt c, causing a rapid adsorption equilibrium within $20 \mathrm{~min}$. Furthermore, these MIMs still remained excellent selectivity and recognition ability according to the selective as well as the competitive adsorption studies, suggesting that the molecularly imprinted mesoporous materials is expected to be used in the field of highly efficient separation and enrichment of proteins.
\end{abstract}

Keywords: amphiphilic ionic liquids; molecularly imprinted mesoporous silica; epitope imprinting; Cytochrome c

\section{Introduction}

Along with the wide development of bioseparetion, biosensing or biomedical materials, the separation and identification of proteins have drawn great attention recently [1]. In the past, the detection of proteins was almost always based on the antigen-antibody reactions, however, the high cost and structural sensitivity somewhat hindered the recycling of antibodies [2]. Molecular imprinting technology (MIT) is an emerging separation method that could achieve the fast and high selective separation of the target molecule with an inexpensive and stabilized biomaterial [3,4]. Nowadays, numerous molecularly imprinted polymers (MIPs) were developed and applied in small template molecules, while the imprinting of proteins still has limitations because of the huge molecular size, flexible conformation, and complex structures $[5,6]$. In order to overcome these challenges, researchers have proposed epitope imprinting $[7,8]$, which is based on using a specific fragment of protein 
as template. Those obtained MIPs by epitope imprinting had the ability to recognize the whole protein $[9,10]$. However, along with the low conformation destructiveness of the epitope imprinting system, some new problems emerges, i.e., how to get enough surface area to reach a high total amount of the recognized target proteins.

Ordered mesoporous silica materials [11-13] with a large surface area was a desired substrate to increase the imprinted sites amounts and enhance the adsorption capacity of target molecule. By making use of the interactions between the surfactant and template, it could be ensured that a portion of the template remained at the surface of micelles [14]. Then, functional monomers and a cross-linker could be copolymerized in the presence of the template protein. After the elution of template, one-step interfacial molecularly imprinted mesoporous silica was obtained. Chen et al. prepared an adenosine monophosphate (AMP)-imprinted mesoporous silica nanoparticle materials (MSNs) with the pore diameter of $2.3 \mathrm{~nm}$ and the BET surface area of $833 \mathrm{~m}^{2} \cdot \mathrm{g}^{-1}$ [15]. The obtained MIPs significantly improved the imprinting efficiency and binding properties toward AMP. Moreover, the tunable pore sizes of the mesoporous materials provided an enough space for the mass transfer of biomacromoleucles, such as proteins [16]. The critical factor is developing a surfactant to controllably grow a mesoporous with easily accessible mesopore, so as to meet the requirements in immobilization of template. Unfortunately, the pore size of some mesoporous support materials by using trimethylammonium bromide (CTAB), as the surfactant is less than the mean size of proteins $[17,18]$, which would reduce the adsorption performance of imprinted polymers for proteins. Therefore, suitable alternatives to CTAB, which not only act as a surfactant, but also generate suitable sizes of mesopores and channels for the diffusion of proteins, are of great importance.

Amphiphilic ionic liquids (ILs) consisting of an imidazolium cation and a hydrophobic long alkyl chain along with a kosmotropic anion could direct the formation of mesophase in the synthesis system and produce well-ordered mesoporous materials [19-21]. The mesopore size can be tuned by varying the length of the alkyl chain and the anion [22]. In addition, the researchers have shown that ILs with an imidazolium cation as the polar group could provide multiple interactions in immobilizing template molecules [23-25], which ensured the adsorption capacity of MIPs. Recently, our group reported an interfacial molecularly imprinted microspheres by using imidazolium-based amphiphilic ionic liquid (IL) as emulsifier and suggested that the amphiphilic IL could immobilize protein at the liquid-water interface by intermolecular forces [26]. Therefore, taking into consideration the potential of ILs to adjust mesopore diameter and provide multiple interactions, designing an imidazolium-based amphiphilic IL as surfactant would improve the adsorption performance of MIPs.

Based on the above reasons, in order to improve the adsorption performance of MIPs, molecularly imprinted mesoporous materials (MIMs) were synthesized to enrich and detect Cytochrome c (Cyt c) by using the surface-exposed C-terminal fragment of Cyt c (AYLKKATNE) as template. Amphiphilic IL 1-octadecyl-3-methylimidazolium chloride $\left(\mathrm{C}_{18} \mathrm{MIMCl}\right)$ was utilized as surfactant to control the mesopore size and immobilize template. The morphologies and structures of MIMs were characterized by transmission electron microscope (TEM), Brunauer-Emmett-Teller (BET) nitrogen adsorption and thermo-gravimetric analysis (TGA). Furthermore, the adsorption properties, specific recognition ability, and reusability of MIMs for Cyt c were systematically investigated.

\section{Experimental}

\subsection{Materials}

1-Chlorooctadecane were obtained from Macklin (Shanghai, China). $\mathrm{NaOH}, \mathrm{HCl}$, methanol, ethanol and tetrahydrofuran (THF) were provided by Kermel (Tianjin, China). The monomers 3-Aminopropyltriethoxysilane (APTES, Aldrich, Shanghai, China) and 1-Propyltrimethoxysilane3-methylimidazolium chloride (PTESMIC, Cheng Jie, Shanghai, China) were used without further purification. Tetraethyl orthosilicate (TEOS, $99 \%$ ) and 1-Methylimidazole were obtained from Aladdin (Shanghai, China). Cytochrome c (Cyt c, $\left.M_{\mathrm{w}}=12.4 \mathrm{kDa}, \mathrm{p} I=11.2\right)$ was purchased from Macklin 
(Shanghai, China). Lysozyme (Lyz, $\left.M_{\mathrm{w}}=13.4 \mathrm{kDa}, \mathrm{p} I=9.6\right)$ and Ovalbumin (OVA, $M_{\mathrm{w}}=45.0 \mathrm{kDa}$, $\mathrm{p} I=4.7)$ were provided by MP Biomedicals. Bovine hemoglobin $\left(\mathrm{BHb}, M_{\mathrm{W}}=64 \mathrm{kDa}, \mathrm{p} I=6.9\right)$ and Bovine serum album (BSA, $M_{\mathrm{w}}=67 \mathrm{kDa}, \mathrm{p} I=4.9$ ) were purchased from Sigma-Aldrich. The peptide chains, including C-terminal fragment of Cyt c (AYLKKATNE), were synthesized by KareBay (Ningbo, China).

\subsection{Synthesis of Amphiphilic Ionic Liquid $\mathrm{C}_{18} \mathrm{MIMCl}$}

The synthesis of $\mathrm{C}_{18} \mathrm{MIMCl}$ was performed according to a reported route [27]. As a typical synthesis process, 1-Methylimidazole $(0.1 \mathrm{~mol})$ was mixed with 1 -Chlorooctadecane $(0.1 \mathrm{~mol})$. The above-mixture was put into a $250 \mathrm{~mL}$ flask with refluxing at $90{ }^{\circ} \mathrm{C}$ for $24 \mathrm{~h}$. When cooling to room temperature, a kind of white solid was obtained. Then, the product was further purified by recrystallization in THF. After washing several times with THF, the resulting white powder was collected by filtration and dried under vacuum at room temperature. The structure of $\mathrm{C}_{18} \mathrm{MIMCl}$ is shown in Figure 1.

${ }^{1} \mathrm{H} \mathrm{NMR}\left(400 \mathrm{MHz}, \mathrm{CDCl}_{3}\right): \delta 10.34(\mathrm{~s}, 1 \mathrm{H}), 7.58(\mathrm{~s}, 1 \mathrm{H}), 7.38(\mathrm{~s}, 1 \mathrm{H}), 4.28(\mathrm{t}, J=7.4 \mathrm{~Hz}, 2 \mathrm{H}), 4.09(\mathrm{~s}$, $3 \mathrm{H}), 1.92-1.80(\mathrm{~m}, 2 \mathrm{H}), 1.35-1.10(\mathrm{~m}, 22 \mathrm{H}), 0.84(\mathrm{t}, J=6.8 \mathrm{~Hz}, 3 \mathrm{H})$.

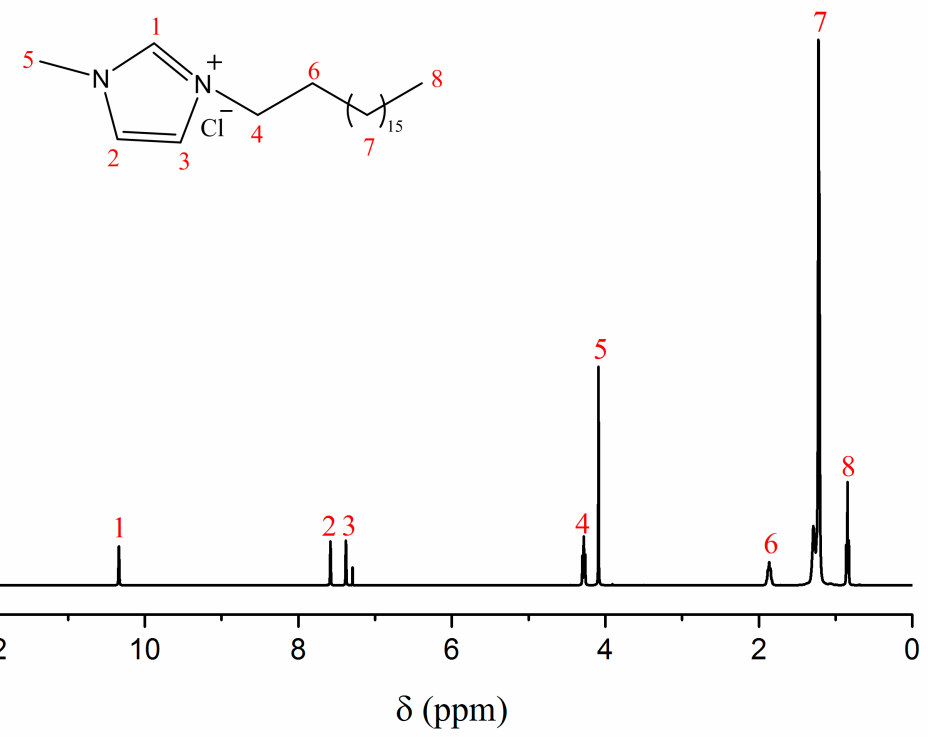

Figure 1. ${ }^{1} \mathrm{H}$ NMR spectrum of $\mathrm{C}_{18} \mathrm{MIMCl}$ in $\mathrm{CDCl}_{3}$.

\subsection{Preparation of Molecularly Imprinted Mesoporous Materials (MIMs)}

Firstly, the $\mathrm{C}_{18} \mathrm{MIMCl}$ and $\mathrm{NaOH}(0.17 \mathrm{~g})$ were dissolved in distilled water $(288 \mathrm{~mL})$ simultaneously. Then, the solution was transferred into a $500 \mathrm{~mL}$ three-necked round-bottomed flask and was stirred at $80{ }^{\circ} \mathrm{C}$ for $15 \mathrm{~min}$ at a speed of $700 \mathrm{rpm}$. Subsequently, $15 \mathrm{mg}$ of template (C-terminal peptides of Cyt c, as AYLKKATNE), TEOS $(2.5 \mathrm{~mL})$, APTES $(0.1 \mathrm{~mL})$ and PTESMIC $(0.38 \mathrm{~g})$ were added dropwise to the mixture and then reacted at $400 \mathrm{rpm}$ for $2 \mathrm{~h}$. Finally, the obtained white powder was washed with ethanol for several times and evaporated under vacuum at $40^{\circ} \mathrm{C}$ for further use. Additionally, the complete removal of $\mathrm{C}_{18} \mathrm{MIMCl}$ and nonapeptide from MIMs was implemented with Soxhlet extraction method by mixing $\mathrm{HCl}(36 \%, 2.5 \mathrm{~mL})$ and methanol $(150 \mathrm{~mL})$. After that, these imprinted materials (MIMs) were dried under vacuum at $40{ }^{\circ} \mathrm{C}$ for $72 \mathrm{~h}$ to remove residual solvent within the mesoporous materials.

In a parallel, non-imprinted mesoporous materials (NIMs) was prepared by the same procedure, but in the absence of template nonapeptide. 


\subsection{Characterization}

${ }^{1} \mathrm{H}$ NMR spectra of ILs was obtained from a Varian spectrometer at $400 \mathrm{MHz}$ using $\mathrm{CDCl}_{3}$ as the solvent. The morphologies and structures of MIMs and NIMs were determined by transmission electron microscopy (TEM, Talos F200X G2). The surface areas and the pore size distributions were calculated by the Brunauer-Emmett-Teller (BET) and Barrett-Joyner-Halenda (BJH) methods. The content of functional monomers was measured by thermo-gravimetric analysis (TGA, Q50, TA Instruments, Shanghai, China). For the detection of template peptides (AYLKKATNE), Cyt c, and comparative protein, UV-vis spectra were obtained using a UV-2550 spectrophotometer (Shimadzu). Sodium dodecyl sulfate polyacrylamide gel electrophoresis (SDS-PAGE) was performed using a DYY-6C electrophoresis system (Beijing Liuyi Instrument Plant, Beijing, China).

\subsection{Isothermal Rebinding and Dynamic Adsorption}

The dried MIMs/NIMs (50 mg) were dispersed in $5 \mathrm{~mL}$ buffer solution $(\mathrm{pH}=7.4)$ with different concentrations of Cyt c (from 0.2 to $1.4 \mathrm{mg} \cdot \mathrm{mL}^{-1}$ ). After incubation with shaking at room temperature for $24 \mathrm{~h}$, the supernatant was further filtrated through a $0.1 \mu \mathrm{m}$ polyethersulfone syringe filter. Then, the concentration of Cyt $\mathrm{c}$ in the supernatant was determined using a UV-vis spectrophotometer.

The adsorption dynamic studies were performed by detecting the adsorption amount of MIMs/NIMs for Cyt c at regular incubation time. First, $50 \mathrm{mg}$ dried MIMs/NIMs were incubated in $5 \mathrm{~mL}$ phosphate buffer $(\mathrm{pH}=7.4)$ containing $1.0 \mathrm{mg} \cdot \mathrm{mL}^{-1}$ of Cyt $\mathrm{c}$ at $25^{\circ} \mathrm{C}$ for $24 \mathrm{~h}$. Then, the concentration of residual Cyt c solution was measured by UV at different incubation time.

The adsorption amount $Q_{\mathrm{e}}\left(\mathrm{mg} \cdot \mathrm{g}^{-1}\right)$ of MIMs/NIMs for protein was evaluated according to Equation (S1), and the imprinting factor (IF) was calculated by Equation (S2).

\subsection{Selectivity and Competitive Adsorption Experiments}

In order to estimate the selectivity recognition of MIMs for Cyt c, $50 \mathrm{mg}$ dried MIMs/NIMs were incubated in $5 \mathrm{~mL}$ phosphate buffer solution $(\mathrm{pH}=7.4)$ containing target protein Cyt $\mathrm{c}$ and protein analogue (Lyz, $\mathrm{BHb}$ and BSA) separately with a concentration of $1.0 \mathrm{mg} \cdot \mathrm{mL}^{-1}$, and the mixture was shaken at $25^{\circ} \mathrm{C}$ for $24 \mathrm{~h}$. The amount of each protein that was adsorbed by MIMs/NIMs was determined by measuring the UV absorbance.

The competitive adsorption experiment was conducted with adding $50 \mathrm{mg}$ dried MIMs/NIMs into $5 \mathrm{~mL}$ phosphate buffer $(\mathrm{pH}=7.4)$ containing both Cyt $\mathrm{c}$ and its competitor at $25^{\circ} \mathrm{C}$ with each protein concentration of $1.0 \mathrm{mg} \cdot \mathrm{mL}^{-1}$. After incubation for $24 \mathrm{~h}$ under gentle shaking, MIMs/NIMs were removed from the solution by centrifugation and treated first with $5 \mathrm{mM} \mathrm{NaCl}$ to rinse the weakly adsorbed proteins on the mesoporous surface of MIMs/NIMs and then with $0.5 \mathrm{M} \mathrm{NaCl}$ to elute the specifically adsorbed proteins. The specifically adsorbed proteins were desalted by using dialysis tubing with a molecular cutoff of $500 \mathrm{Da}$, and were then freeze-dried for $24 \mathrm{~h}$. Thereafter, the obtained protein was dissolved in $5 \mathrm{~mL}$ phosphate buffer $(\mathrm{pH}=7.4)$ and was analyzed by SDS-PAGE using $12.5 \%$ polyacrylamide separating gel and $5 \%$ polyacrylamide stacking gel.

\subsection{Reusability Experiments}

Reusability is one of an important property of MIPs in practical applications. To evaluate the reusability of the MIMs and NIMs, $50 \mathrm{mg}$ dried MIMs/NIMs were suspended in $5 \mathrm{~mL}$ protein solution $(\mathrm{pH}=7.4)$ with a concentration of $1.0 \mathrm{mg} \cdot \mathrm{mL}^{-1}$. After adsorption and centrifugation, the concentration of Cyt $\mathrm{c}$ residue was determined by UV-vis spectrophotometer. Thereafter, the recovered MIMs were eluted for the removal of the template and were then further reused for subsequent adsorption-desorption cycles. The reusability adsorption experiments were performed six times at ambient temperature by the same batches of MIMs. 


\section{Results and Discussion}

\subsection{The Effect of Alkyl Chain Length of ILs on Mesoporous Diameter}

The appropriate mesopore size could promote the mass transfer and recognition of protein [28]. Cytochrome c (Cyt c), a structurally robust heme protein with dimensions of $\sim 2.6 \mathrm{~nm} \times 3.2 \mathrm{~nm}$ $\times 3.3 \mathrm{~nm}$, was used as the target protein to explore the adsorption and recognition process of proteins that were entering the imprinted sites [29]. In order to explore the suitable pore size for recognition Cyt c, three kinds of ILs were synthesized as surfactants to prepare three mesoporous silica nanoparticle materials (MSNs), which were 1-octyl-3-methylimidazolium chloride ( $\left.{ }_{8} \mathrm{MIMCl}\right)-\mathrm{MSNs}$, 1-tetradecyl-3-methylimidazolium chloride $\left(\mathrm{C}_{14} \mathrm{MIMCl}\right)-\mathrm{MSNs}$, and 1-octadecyl-3-methylimidazolium chloride $\left(\mathrm{C}_{18} \mathrm{MIMCl}\right)-\mathrm{MSNs}$, respectively. The detailed synthesis process of $\mathrm{C}_{8} \mathrm{MIMCl}, \mathrm{C}_{14} \mathrm{MIMCl}$, and $\mathrm{C}_{n} \mathrm{MIMCl}-\mathrm{MSN}$ s were explained in supplementary materials. The structure of $\mathrm{C}_{8} \mathrm{MIMCl}$ and $\mathrm{C}_{14} \mathrm{MIMCl}$ are shown in Figures S1 and S2. The synthetic schematic of $\mathrm{C}_{\mathrm{n}} \mathrm{MIMCl}-\mathrm{MSNs}$ with different pore size was displayed in Scheme S1. Firstly, the ionic liquid was dissolved in an aqueous solution to form micelles, and then the mesoporous material was synthesized by a one-step sol-gel method.

The TEM images of $\mathrm{C}_{n}$ MIMCl-MSNs were showed in Figure S3. It was employed to investigate the morphologies of $C_{n}$ MIMCl-MSNs. The obtained $C_{n}$ MIMCl-MSNs exhibited a spherical shape with ordered mesopores, which confirmed that the $\mathrm{C}_{\mathrm{n}}$ MIMCl-MSNs were prepared successfully. The average pore diameter and specific surface areas of MSNs were conducted by nitrogen adsorption-desorption. As shown in Table 1, the BJH average pore diameters of these materials increased as the alkyl chain of the ILs lengthened. The pore size varied approximately in the range of 1.80-3.60 nm with the varied carbon chain lengths of the used ILs. It was because that the concentrations of ILs were higher than there critical micelle concentration (CMC) in water system, hydrophobic alkyl chain will gather to form the micelles with different diameters. When the micelle rods were removed, mesoporous channels with different diameters were obtained. When compared with $\mathrm{C}_{8} \mathrm{MIM}$-MSNs and $\mathrm{C}_{14}$ MIM-MSNs, $\mathrm{C}_{18}$ MIM-MSNs possessed the most optimal and suitable pore diameter for the mass transfer of Cyt $\mathrm{c}$ in the pore. Therefore, using the amphiphilic IL $\mathrm{C}_{18} \mathrm{MIMCl}$ as surfactant could provide satisfied pore diameter for adsorption of Cyt c by MIMs in rebinding tests.

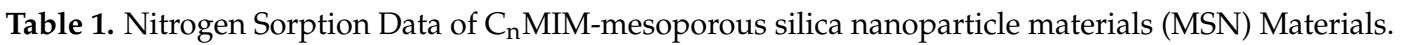

\begin{tabular}{cccc}
\hline $\begin{array}{c}\text { Ionic Liquids } \\
\text { (ILs) }\end{array}$ & $\begin{array}{c}\text { BET Surface Areas } \\
\left(\mathbf{m}^{\mathbf{2}} \mathbf{g}\right)\end{array}$ & $\begin{array}{c}\text { Pore Volume } \\
\left(\mathbf{c m}^{\mathbf{3}} \mathbf{g}\right)\end{array}$ & $\begin{array}{c}\text { BJH Average Pore } \\
\text { Diameter }(\mathbf{n m})\end{array}$ \\
\hline $\mathrm{C}_{8} \mathrm{MIMCl}$ & 1031 & 0.673 & 1.85 \\
$\mathrm{C}_{14} \mathrm{MIMCl}$ & 692 & 0.662 & 2.23 \\
$\mathrm{C}_{18} \mathrm{MIMCl}$ & 795 & 0.810 & 3.58 \\
\hline
\end{tabular}

\subsection{Preparation and Characterization of MIMs and NIMs}

The MIMs was prepared by combining the epitope imprinting technique and sol-gel method (Scheme 1). Based on above pore size experiment results, the amphiphilic IL with an imidazole ring $\left(\mathrm{C}_{18} \mathrm{MIMCl}\right)$ was utilized as surfactant. The nonapeptide template was anchored on the surface of $\mathrm{C}_{18} \mathrm{MIMCl}$ micelle rods through multiple interactions [30] generating surfactant-template complexes. After removal of the surfactant-template complexes, all of the imprinted sites were formed on the surface of mesoporous channels. The obtained MIMs could be an ideal sorbent for the selective enrichment of Cyt c. 


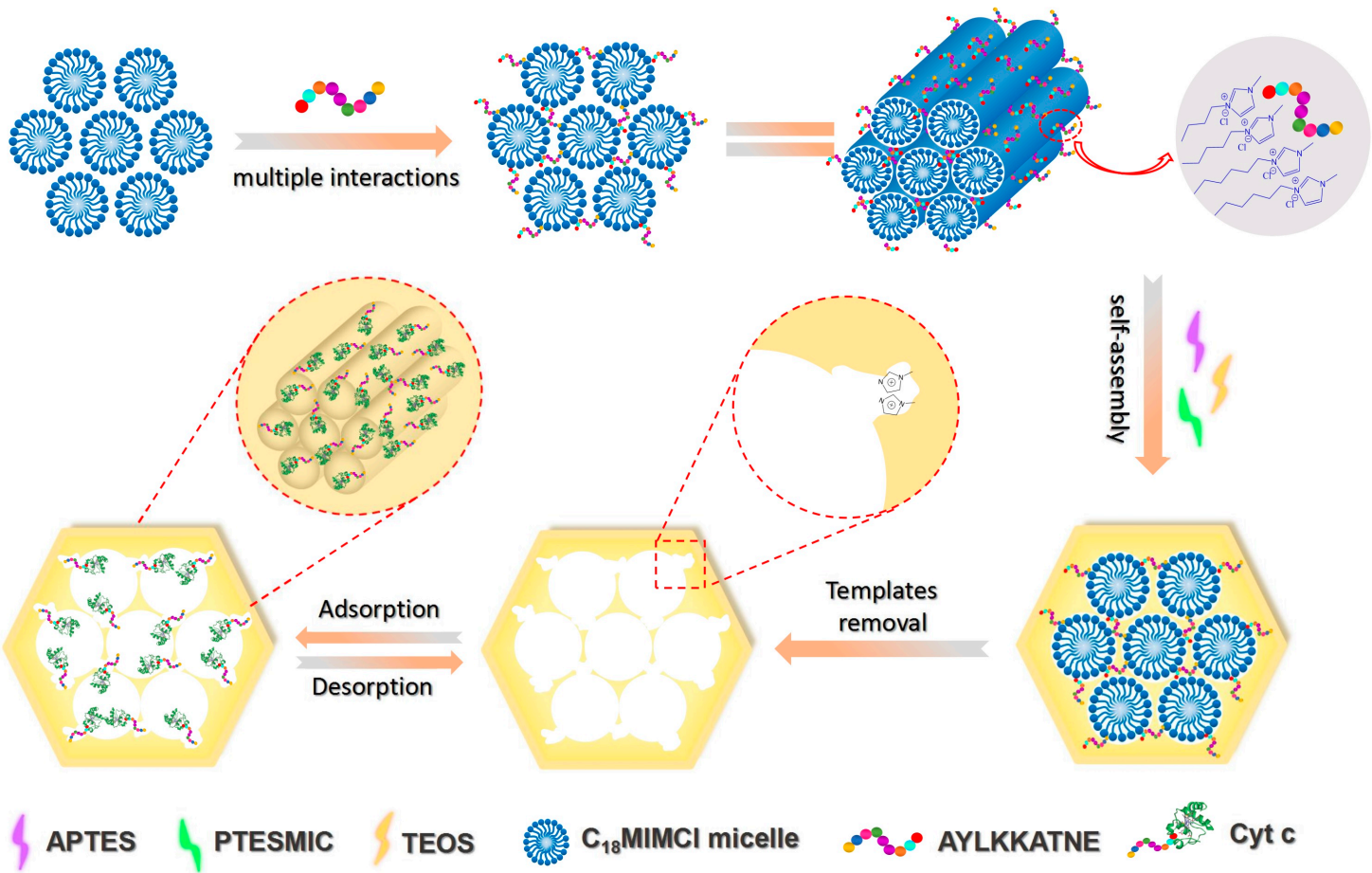

Scheme 1. Schematic illustration of the synthesis procedure of MIMs and the selective process for the enrichment of Cytochrome c (Cyt c) using MIMs.

The TEM images of MIMs and NIMs were showed in Figure 2a,b. It is noted that the nonapeptide-imprinted and non-imprinted mesoporous materials displayed a fibrous porous morphology that is directed by $\mathrm{C}_{18} \mathrm{MIMCl}$. Both the MIMs and NIMs were nearly spherical in shape with an average diameter about $200 \mathrm{~nm}$. The smaller spherical size and regularly ordered mesopores produced a large specific surface area of imprinted mesoporous materials, which will be beneficial to the adsorption performance of MIMs. The average size of MIMs was investigated by dynamic light scattering (DLS). As shown in Figure S4, the size distribution of MIMs was about $200 \mathrm{~nm}$, which was consistent with TEM.
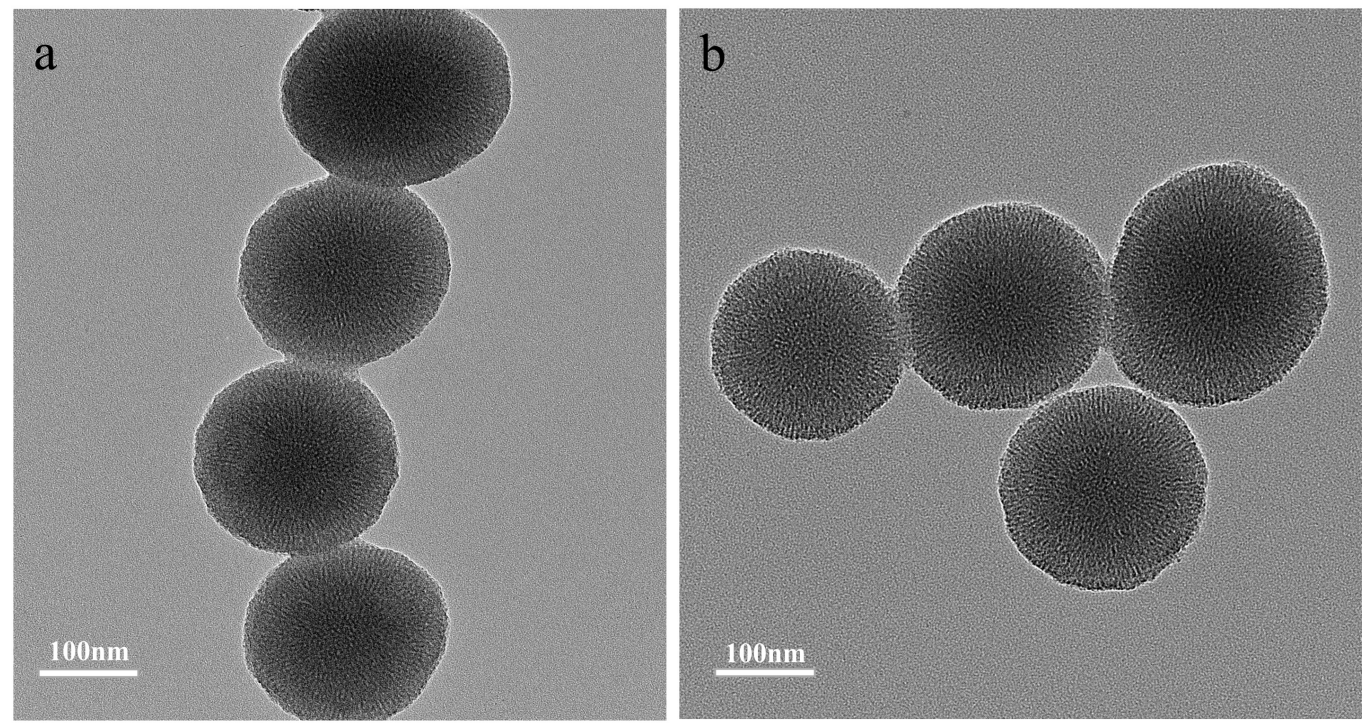

Figure 2. Transmission electron microscope (TEM) images of MIMs (a) and NIMs (b). 
The $\mathrm{N}_{2}$ adsorption-desorption isotherms and pore size distribution of MIMs and NIMs were also performed. As shown in Figure 3a,b, the pore diameter of MIMs and NIMs were measured to be 3.62 and $3.43 \mathrm{~nm}$, and the specific surface areas were calculated to be 824 and $665 \mathrm{~m}^{2} \cdot \mathrm{g}^{-1}$, respectively. According to the mechanism of mesoporous formation, these differences may be attributed to the imprinted cavities mostly embedding in the surface of mesoporous channel of MIMs, which made a local expansion of the regular mesopores. Therefore, the average pore size and specific surface areas were increased. Additionally, the appropriate pore diameter and the larger surface areas of MIMs will contribute to the mass transfer of Cyt $\mathrm{c}$ in the mesopores.
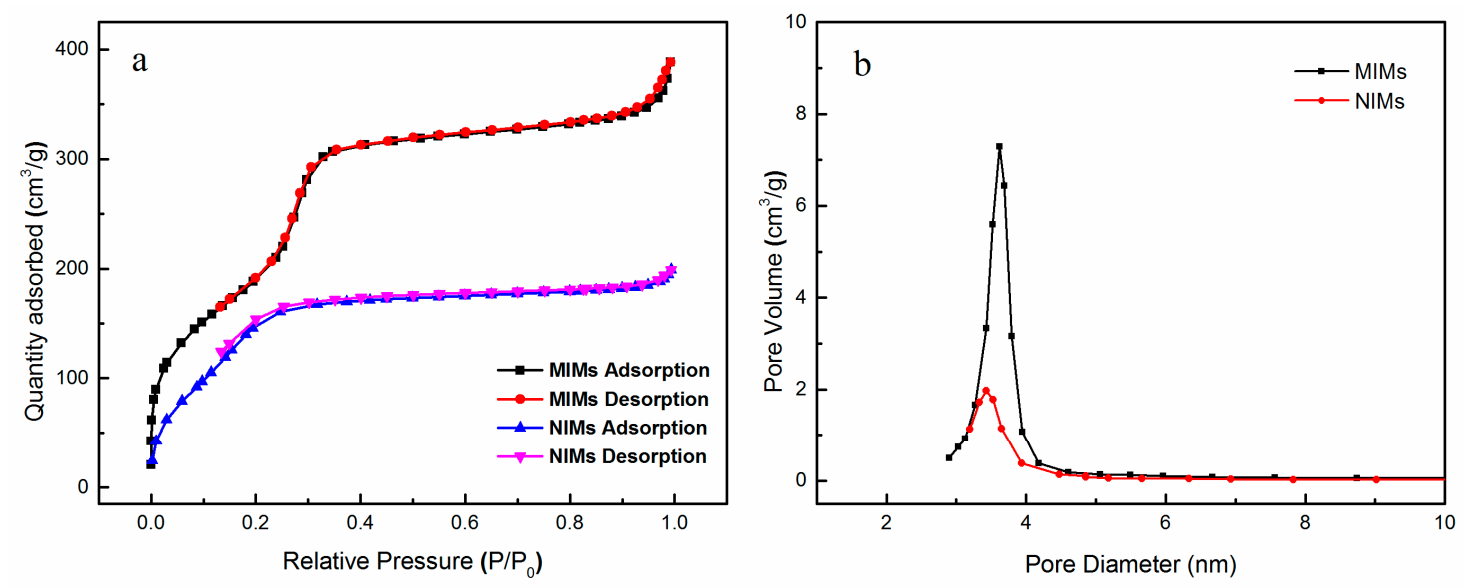

Figure 3. $\mathrm{N}_{2}$ adsorption-desorption isotherms (a) and pore size distribution (b) for molecularly imprinted mesoporous materials (MIMs) and non-imprinted mesoporous materials (NIMs).

The solid content of MIMs and NIMs were studied by TGA, and the results were showed in Figure 4. All materials had slightly decline before temperature rising to $200{ }^{\circ} \mathrm{C}$, which were the weight loss of adsorbed moisture and surface organogels or inorganic gels. When the temperature was increased above $200{ }^{\circ} \mathrm{C}$, the loss of MIMs and NIMs were due to the decomposition of APTES and PTESMIC. This phenomenon demonstrated that the heat losses of MIMs and NIMs were almost identical, indicating that the degree of polymerization of both was consistent. Therefore, the measured value of adsorption property for Cyt c would not be affected by differences in polymerization.

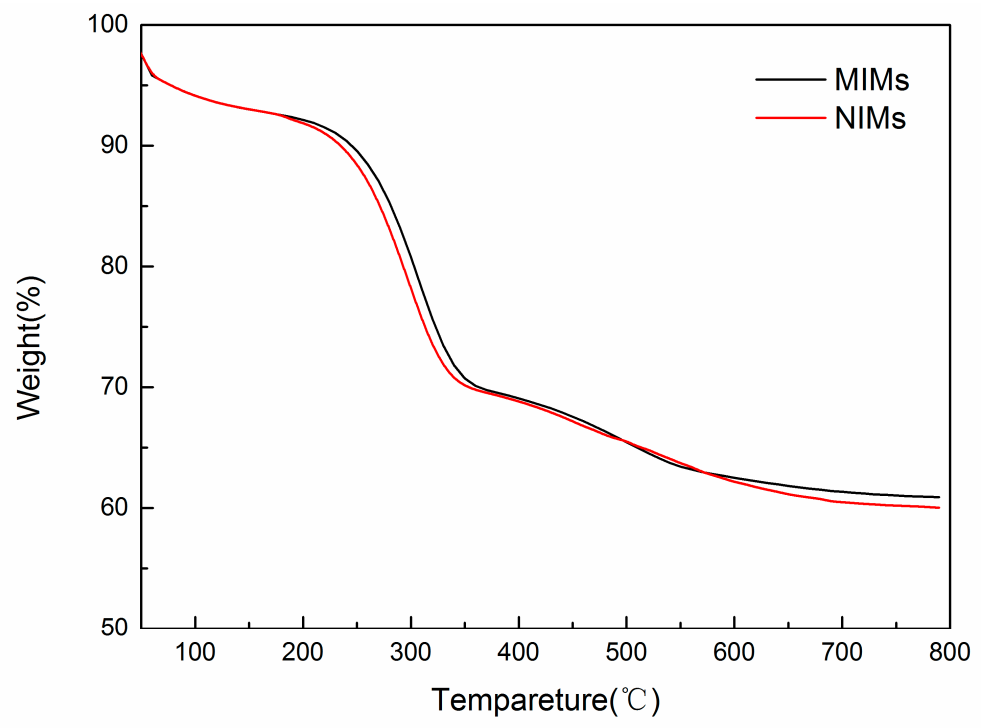

Figure 4. Thermo-gravimetric analysis (TGA) curves of MIMs and NIMs. 


\subsection{Adsorption Properties of MIMs and NIMs}

For investigating the imprinting efficiency and binding properties of MIMs for target protein Cyt c, adsorption isotherm experiments were conducted in Cyt c solutions with a certain concentration. From the Figure 5a, it is easy to observe that the adsorption capacity enhanced with an increasing Cyt c concentration. The adsorption equilibrium capacity $Q_{\mathrm{e}}$ of MIMs increased sharply with the initial concentration of Cyt $\mathrm{c}$, and then saturated over $1.0 \mathrm{mg} \cdot \mathrm{mL}^{-1}$, while the maximum adsorption capacity of Cyt c reached $86.47 \mathrm{mg} \cdot \mathrm{g}^{-1}$. However, the $Q_{\mathrm{e}}$ of NIMs for Cyt c was much lower than that of MIMs and the maximum adsorption amount was only $24.85 \mathrm{mg} \cdot \mathrm{g}^{-1}$, which showed that MIMs had a higher binding ability than that of NIMs. The relative high adsorption capacity might be attributed to the multiple interactions (such as hydrogen bonding, $\pi-\pi$ stacking, ion-ion electrostatic, and van der Waals interactions, etc.) afforded by $\mathrm{C}_{18} \mathrm{MIMCl}$ [31]. Particularly, the ion-ion electrostatic interaction provided by imidazolium group of $\mathrm{C}_{18} \mathrm{MIMCl}$ and PTESMIC is much stronger than the other interactions [32], which could induce the aggregation of oppositely charged nonapeptide around the micelles and facilitated the formation of more imprinting sites on the mesoporous surface. The maximum IF was calculated to be 3.48, indicating that the MIMs had better specific recognition when compared with NIMs, because the specific recognition cavities were generated on the surface of mesoporous channels of MIMs in the imprinting process.
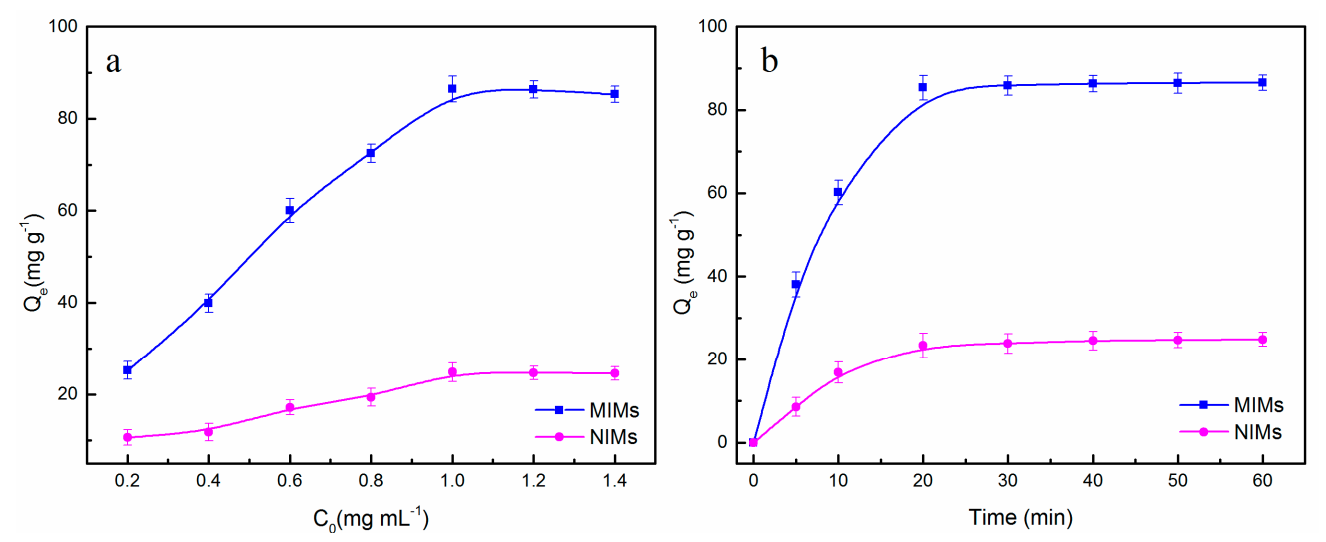

Figure 5. Adsorption isotherm of MIMs and NIMs with Cyt c (a); Adsorption dynamic curves of MIMs and NIMs with Cyt c (b).

The experimental data was fitted by different isotherm models, including Langmuir model (Equation (S3)) and Freundlich model (Equation (S4)). The Langmuir model assumes that adsorption took place on a homogeneous surface with identical active sites and uniform energies, while the Freundlich model assumes that adsorption occurred on a heterogeneous surface with the exponential distribution of active sites and energies [33]. The calculated parameters were listed in Table 2. As shown in Table 2, the Langmuir model gave a better fitting in the range of concentrations than that Freundlich model via the correlation coefficient $\left(R^{2}\right)$ value, which showed that the adsorption of MIMs to the target protein Cyt $\mathrm{c}$ is monolayer adsorption. Because the MIMs was prepared by using nonapeptide as template via epitope imprinting approach to separate and recognize Cyt $\mathrm{c}$. The pore size of the imprinted sites is slightly larger than the average mesopore size around $3.62 \mathrm{~nm}$. Therefore, the MIMs was more likely to form a single specific adsorption for Cyt $\mathrm{c}$ at the imprinted sites in a limited space.

Table 2. Isotherm model and constants of MIMs, NIMs for Cyt c.

\begin{tabular}{ccccccc}
\hline Isotherm Model & \multicolumn{3}{c}{ Langmuir } & \multicolumn{3}{c}{ Freundlich } \\
\cline { 2 - 6 } Materials & $\boldsymbol{Q}_{\max }\left(\mathbf{m g} \cdot \mathbf{g}^{-\mathbf{1}}\right)$ & $\left.\boldsymbol{K}_{\mathbf{L}} \mathbf{( m g} \cdot \mathbf{m L}^{-\mathbf{1}}\right)$ & $\boldsymbol{R}^{\mathbf{2}}$ & $\left.\boldsymbol{K}_{\mathbf{F}} \mathbf{( m g} \cdot \mathbf{g}^{-\mathbf{1}}\right)$ & $\boldsymbol{n}^{2}$ & $\boldsymbol{R}^{\mathbf{2}}$ \\
\hline MIMs & 156.05 & 1.0192 & 0.9632 & 77.29 & 1.6931 & 0.9340 \\
NIMs & 38.61 & 1.3998 & 0.9256 & 22.12 & 1.9729 & 0.9291 \\
\hline
\end{tabular}


For NIMs, the Freundlich model and the Langmuir model yielded a similar fit to the equilibrium data in terms of the correlation coefficients $\left(R^{2}\right)$ values, which was related to the random arrangements of functional groups and the absence of specific recognition sites in NIMs.

To determine the rate of adsorption and the binding capacities as a function of time, the adsorption dynamics of MIMs and NIMs were carried out by using $1.0 \mathrm{mg} \cdot \mathrm{mL}^{-1} \mathrm{Cyt} \mathrm{c}$ buffer solution at $25^{\circ} \mathrm{C}$. As shown in Figure 5b, both MIMs and NIMs showed a rapid increase during the first $20 \mathrm{~min}$, and then the adsorption process reached equilibrium after $20 \mathrm{~min}$. Obviously, the adsorption rate and adsorption capacities of MIMs for Cyt $\mathrm{c}$ in the initial phase were higher than that of NIMs. When compared with the previous works of our group [26,34], the imprinted mesoporous materials showed a faster adsorption rate for target protein. It is attributed to the specific recognition sites increased by the large internal surface areas of mesoporous silica, and highly accessible sites locating on the wall of the mesoporous, which also be responsible for the excellent adsorption performance of MIMs. Moreover, it also implied that the imprinted mesoporous materials prepared by epitope imprinting method can achieve rapid and specific adsorption of Cyt $\mathrm{c}$.

The controlling mechanism of dynamic binding process was further investigated by the pseudo-first-order and pseudo-second-order kinetic models via Equations (S5) and (S6). In general, the pseudo-first-order model indicates that the occupation rate of adsorption sites is proportional to the number of unoccupied sites, whereas the pseudo-second-order model assumes that the adsorption rate is controlled by chemical adsorption [35]. According to the correlation coefficient $\left(R^{2}\right)$ value in Table 3, the pseudo-second-order kinetic model showed a better correlation with the MIMs, which demonstrated that chemical adsorption might be the rate-limiting step in the process of recognition, indicating that imprinted sites were actually formed and that they are functionally and sterically complementary affinity to nonapeptide fragment on Cyt c.

Table 3. Kinetic constants of the pseudo-first-order and pseudo-second-order.

\begin{tabular}{|c|c|c|c|c|c|c|c|}
\hline \multirow[b]{2}{*}{ Materials } & \multirow[b]{2}{*}{$Q_{e, e}{ }^{a}\left(m g \cdot g^{-1}\right)$} & \multicolumn{3}{|c|}{ Pseudo-First-Order } & \multicolumn{3}{|c|}{ Pseudo-Second-Order } \\
\hline & & $Q_{e, c}{ }^{b}\left(m g \cdot g^{-1}\right)$ & $K_{1}\left(\min ^{-1}\right)$ & $R^{2}$ & $Q_{e, c}{ }^{b}\left(m g \cdot g^{-1}\right)$ & $K_{1}\left(\mathrm{~g} \mathrm{mg}^{-1} \cdot \min ^{-1}\right)$ & $R^{2}$ \\
\hline MIMs & 86.47 & 87.86 & 0.1209 & 0.9784 & 101.10 & 0.0015 & 0.9948 \\
\hline NIMs & 24.85 & 25.11 & 0.1048 & 0.9753 & 29.71 & 0.0040 & 0.9919 \\
\hline
\end{tabular}

${ }^{\mathrm{a}} Q_{\mathrm{e}, \mathrm{e}}$ is the experimental value of $Q_{\mathrm{e}} ;{ }^{\mathrm{b}} Q_{\mathrm{e}, \mathrm{c}}$ is the calculated value of $Q_{\mathrm{e}}$.

\subsection{Selectivity Study}

The selective adsorption experiment of MIMs and NIMs for different proteins was performed in buffer solution $(\mathrm{pH}=7.4)$ with a feed concentration of $1.0 \mathrm{mg} \cdot \mathrm{mL}^{-1}$. Three proteins of $\mathrm{BSA}, \mathrm{BHb}$, and Lyz were chosen as reference proteins for Cyt c. As presented in Figure 6, the adsorption capacities of MIMs for BSA and $\mathrm{BHb}$ were much lower than that for Cyt c. Owing to the conformational differences among Cyt c, BSA, and BHb, the imprinted cavities of MIMs more matched with the C-terminal nonapeptide of Cyt c. However, the adsorption capacities of MIMs for another reference protein, Lyz, was slightly higher than that for BSA and BHb because Lyz has the close isoelectric point $(\mathrm{p} I)$ and molecular wight $\left(M_{\mathrm{W}}\right)$ with Cyt $\mathrm{c}$ and can enter the mesopores causing high non-specific adsorption capacity. The corresponding imprinting factor IF of MIMs for BSA, BHb and Lyz were also reported in Figure 6. IFs of these proteins decreased in the order of Cyt $\mathrm{c}>\mathrm{BSA}>\mathrm{BHb}>\mathrm{Lyz}$, which indicated that the imprinted sites were closely match with Cyt $\mathrm{c}$ in the interaction sites and the three-dimensional space. 


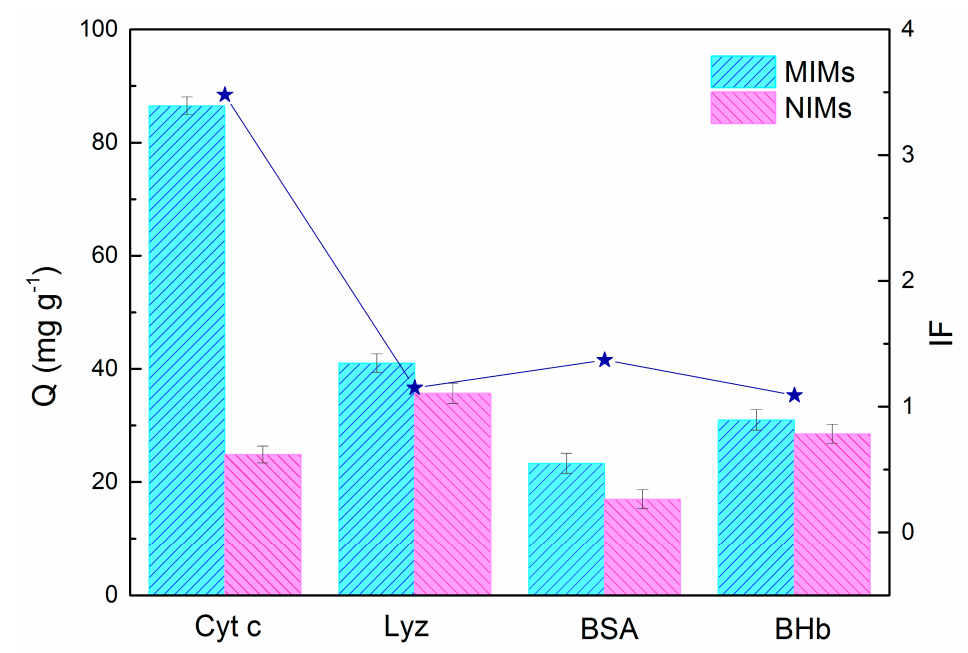

Figure 6. Selectivity of MIMs and NIMs in the adsorption of proteins.

The above selective adsorption experiment showed that Lyz is a potential competitor to Cyt c. In order to further investigate the selective recognition of MIMs for Cyt c, the binary competitive adsorption experiments were performed in complex samples containing Cyt $\mathrm{c}$ and Lyz with concentration of $1.0 \mathrm{mg} \cdot \mathrm{mL}^{-1}$. As presented in Figure 7, the adsorption capacity of MIMs for Cyt $\mathrm{c}$ was higher than that of Lyz, suggesting that the functional groups that were located at imprinted cavities could offer functionally complementary affinity toward Cyt $\mathrm{c}$ in above complex environment, as compared with reference protein Lyz, and thus imprinted cavities had excellent specificity for Cyt c.

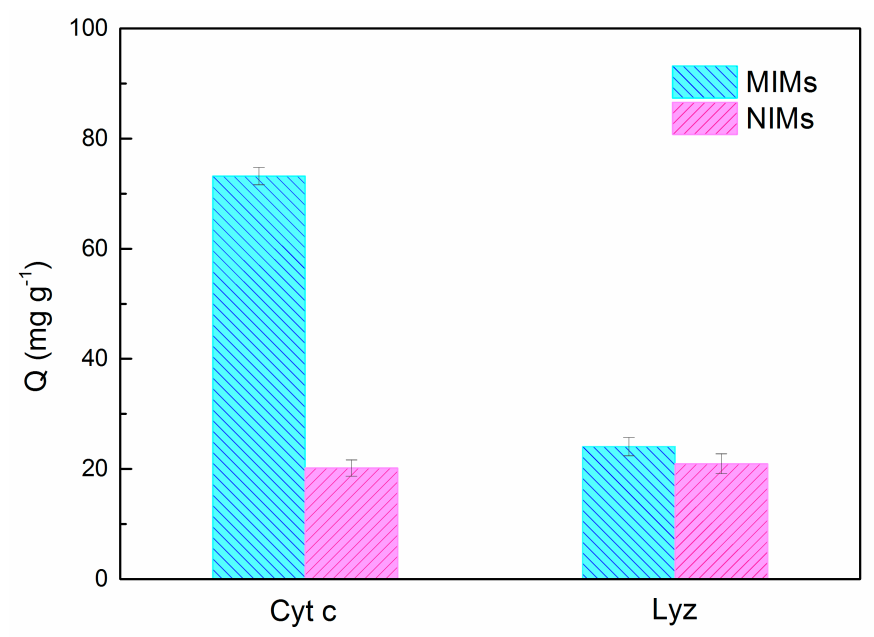

Figure 7. Selective binding of MIMs and NIMs for Cyt c and Lyz, respectively.

\subsection{Competitive Batch Rebinding Tests}

To further illustrate the specific recognition property of the MIMs for the Cyt c, BSA, and OVA were used as the competitive proteins in the buffer solution. As shown in Figure 8, lane 2 presented BSA, OVA and Cyt c sequentially with each concentration of $1.0 \mathrm{mg} \cdot \mathrm{mL}^{-1}$. After the adsorption by MIMs, the content of Cyt $\mathrm{c}$ in the mixed solution decreased significantly (lane 2 to lane 3 ). The intensity of the template Cyt c band eluted from MIMs (lane 4) was higher than that of corresponding NIMs (lane 5), revealing that the MIMs had a better ability to specifically recognize Cyt c. Moreover, the bands of BSA and OVA in lane 4 were shallower than the lane 2, suggesting that a little amount of BSA and OVA was captured by MIMs. In general, MIMs could selectively capture and effectively enrich Cyt c from the complex protein mixture. 


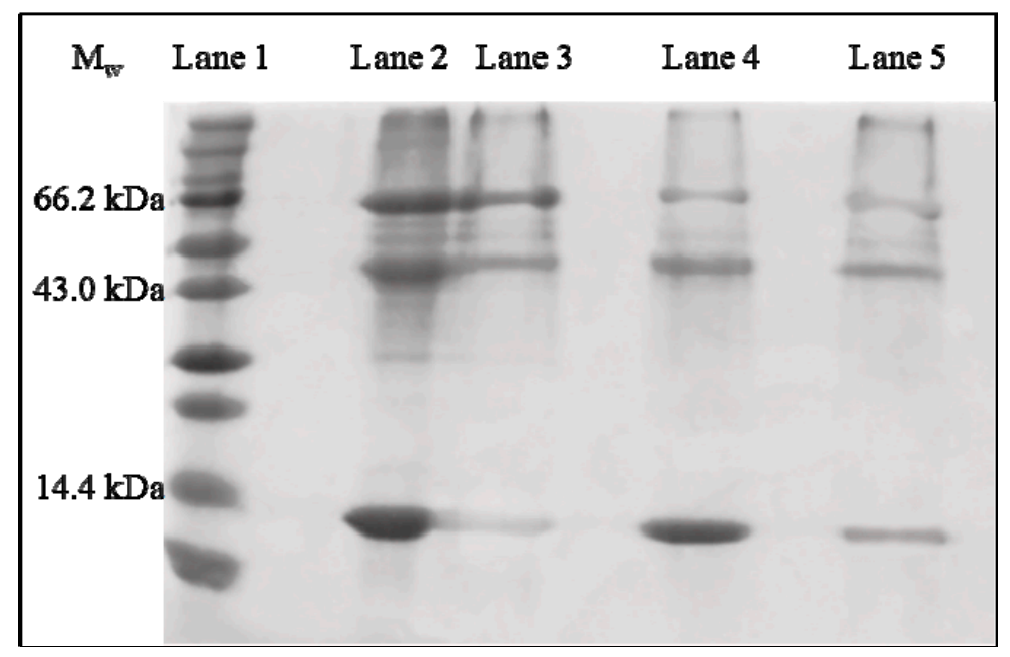

Figure 8. Sodium dodecyl sulfate polyacrylamide gel electrophoresis (SDS-PAGE) results of competitive adsorption experiment. Lane 1, protein molecular weight marker; Lane 2, solution of mixture of Bovine serum album (BSA), Ovalbumin (OVA), and Cyt c; Lane 3, the protein in the mixed solution after adsorption by MIMs; Lane 4, the protein eluted from MIMs; Lane 5, the protein eluted from NIMs.

\subsection{Comparison of Imprinting Methods for Cyt C}

To check the superior adsorption performance of MIMs with amphiphilic ILs as the surfactant to control pore size and immobilize template, we investigated the adsorption capacity and the equilibrium rate of MIMs for Cyt $\mathrm{c}$ in other related researches. As shown in Table 4, owing to advantages of the high specific surface areas of mesoporous silica and the epitope imprinting method, this new imprinting strategy could obtain much higher binding capacity toward Cyt $\mathrm{c}$ than that of others imprinted polymers [36-38]. From the comparison of the adsorption rate, we could conclude that this approach still displayed the rapid adsorption equilibrium on the basis of a superior adsorption capacity. That further demonstrated the MIMs have the potential to be applied in the field of molecular imprinting.

Table 4. Comparison of different methods of imprinting Cyt c.

\begin{tabular}{|c|c|c|c|c|c|}
\hline Carrier & Imprinting Strategies & Recongation Interactions & Adsorption Equilibrium & $Q\left(\mathrm{mg} \cdot \mathrm{g}^{-1}\right)$ & Ref. \\
\hline BC nanofibers & Protein imprinting & metal ion coordination & $10 \mathrm{~min}$ & 36.4 & [36] \\
\hline $\mathrm{Fe}_{3} \mathrm{O}_{4} @ \mathrm{SiO}_{2}$ & Epitope imprinting & Multiple & $2 \mathrm{~h}$ & 67.6 & [37] \\
\hline Organic polymers & Protein imprinting & Hydrogen bond & $4 \mathrm{~h}$ & 67.4 & [38] \\
\hline Mesoporous silica & Epitope imprinting & Multiple & $20 \mathrm{~min}$ & 86.47 & This method \\
\hline
\end{tabular}

\subsection{Reusability}

Reproducibility is one of an important criterion to evaluate the property of imprinted materials in the practical purposes. Therefore, the reusability of MIMs for six adsorption-desorption cycles was investigated in Cyt c solution ( $\mathrm{pH}=7.4$ ) with a feed concentration of $1.0 \mathrm{mg} \cdot \mathrm{mL}^{-1}$. As shown in Figure 9 , the adsorption capacity of MIMs decreased slightly after each elution step, and $13.43 \mathrm{mg} \cdot \mathrm{g}^{-1}$ adsorption capacity was lost after six cycles. In order to observe the decreased adsorption amount of each elution step more directly, the statistical analysis of the reusability of MIMs was showed in Table S1. Because some recognition sites in the mesopore might be destroyed or blocked during the washing procedure, which were not helpful to recognize the Cyt c anymore. When compared to MIMs, there was little decrease in case of adsorption capacity of NIMs because no specific adsorption sites were located in them. 


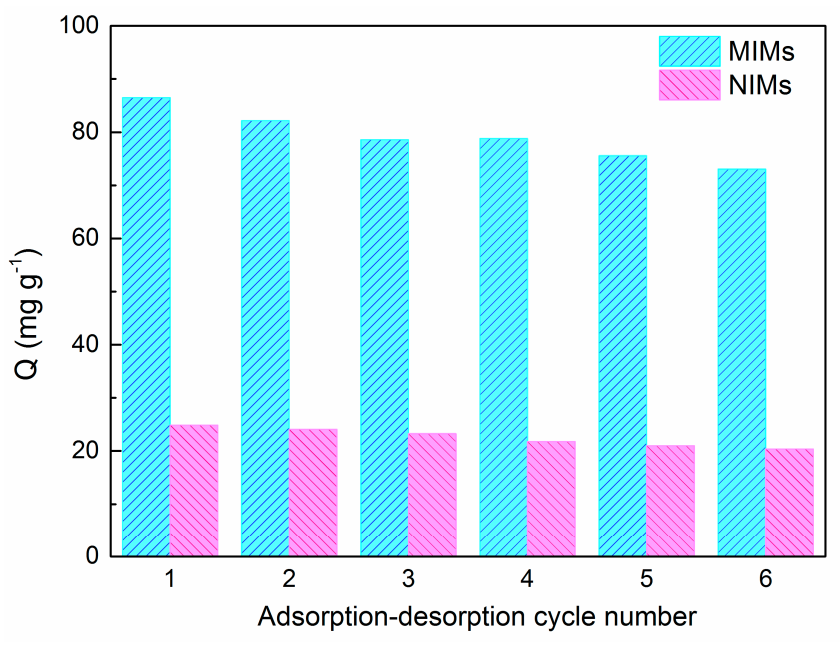

Figure 9. Reusabilities of MIMs and NIMs.

\section{Conclusions}

In this work, we have synthesized molecularly imprinted mesoporous materials (MIMs) via epitope imprinting and the sol-gel method. Amphiphilic IL $\mathrm{C}_{18} \mathrm{MIMCl}$ was used as the surfactant to direct the formation of mesopores and immobilize template. The multiple interactions between $\mathrm{C}_{18} \mathrm{MIMCl}$ and nonapeptide could ensure the positioning of nonapeptide at the micelle interface, which was primary for the generation of imprinted cavities at the surface of mosoporous channels. The prepared imprinted mesoporous materials provided a suitable pore diameter to promote the mass transfer of Cyt c spaciously. The large specific surface areas of MIMs guaranteed enough recognition sites. Due to these advantages, the MIMs not only exhibited high adsorption capacity $\left(86.47 \mathrm{mg} \cdot \mathrm{g}^{-1}\right)$ and rapid adsorption equilibrium $(20 \mathrm{~min})$, but also displayed superior specificity and selectivity toward Cyt $\mathrm{c}$ by analyzing the selectivity and competitive adsorption experiments. Furthermore, the reusability makes it an ideal candidate to be applied in protein purification and separation science. We concluded that the strategy of combining molecular imprinting mesoporous materials and amphiphilic ILs can yield smart imprinted materials with rapid adsorption rate, excellent adsorption performance, and high specificity and selectivity, thus advancing the field of protein imprinting one step further.

Supplementary Materials: The following are available online at www.mdpi.com/2073-4360/10/3/298/s1, Figure S1: ${ }^{1} \mathrm{H}$ NMR spectrum of $\mathrm{C}_{8} \mathrm{MIMC}$ in $\mathrm{CDCl}_{3}$; Figure S2: ${ }^{1} \mathrm{H}$ NMR spectrum of $\mathrm{C}_{14} \mathrm{MIMCl}$ in $\mathrm{CDCl}_{3}$; Figure S3: The TEM images of $\mathrm{C}_{8}$ MIM-MSNs (a), $\mathrm{C}_{14}$ MIM-MSNs $(\mathbf{b})$ and $\mathrm{C}_{18}$ MIM-MSNs (c); Figure S4: Size distributions of MIMs as measured by dynamic light scattering in water; Scheme S1: Schematic illustration of the synthesis procedure of MSNs; Table S1: The statistical analysis of the reusabilities of MIMs.

Acknowledgments: The authors are grateful for the financial support of the National Natural Science Foundation of China (Grant No. 51433008) and the Natural Science Basic Research Plan in Shaanxi Province of China (Grant No. 2017JQ2019).

Author Contributions: Zhiling Li, Ping Guan and Xiaoling Hu conceived and designed the experiments; Zhiling Li, Yuan Tian and Yarong Xu performed the experiments; Zhiling Li and Shichao Ding analyzed the data; Zhiling Li and Liwei Qian wrote the paper. All authors agree on the order of attribution and have given approval to the final version of the manuscript.

Conflicts of Interest: The authors declare no conflict of interest.

\section{References}

1. He, X.; Chen, Y.; Wang, K.; Wu, P.; Gong, P.; Huo, H. Selective separation of proteins with pH-dependent magnetic nanoadsorbents. Nanotechnology 2007, 18, 365604. [CrossRef] 
2. MacCallum, R.M.; Martin, A.C.R.; Thornton, J.M. Antibody-antigen interactions: Contact analysis and binding site topography. J. Mol. Biol. 1996, 262, 732-745. [CrossRef] [PubMed]

3. Cheong, W.J.; Ali, F.; Choi, J.H.; Lee, J.O.; Sung, K.Y. Recent applications of molecular imprinted polymers for enantio-selective recognition. Talanta 2013, 106, 45-59. [CrossRef] [PubMed]

4. Martín-Esteban, A. Molecularly-imprinted polymers as a versatile, highly selective tool in sample preparation. TrAC Trends Anal. Chem. 2013, 45, 169-181. [CrossRef]

5. Qian, L.; Hu, X.; Guan, P.; Wang, D.; Li, J.; Du, C.; Song, R.; Wang, C.; Song, W. The effectively specific recognition of bovine serum albumin imprinted silica nanoparticles by utilizing a macromolecularly functional monomer to stabilize and imprint template. Anal. Chim. Acta 2015, 884, 97-105. [CrossRef] [PubMed]

6. Li, S.; Cao, S.; Whitcombe, M.J.; Piletsky, S.A. Size matters: Challenges in imprinting macromolecules. Prog. Polym. Sci. 2014, 39, 145-163. [CrossRef]

7. Nishino, H.; Huang, C.S.; Shea, K.J. Selective protein capture by epitope imprinting. Angew. Chem. Int. Ed. 2006, 45, 2392-2396. [CrossRef] [PubMed]

8. Tai, D.F.; Lin, C.Y.; Wu, T.Z.; Chen, L.K. Recognition of dengue virus protein using epitope-mediated molecularly imprinted film. Anal. Chem. 2005, 77, 5140-5143. [CrossRef] [PubMed]

9. Yang, Y.Q.; He, X.W.; Wang, Y.Z.; Li, W.Y.; Zhang, Y.K. Epitope imprinted polymer coating CdTe quantum dots for specific recognition and direct fluorescent quantification of the target protein bovine serum albumin. Biosens. Bioelectron. 2014, 54, 266-272. [CrossRef] [PubMed]

10. Rachkov, A.; Minoura, N. Recognition of oxytocin and oxytocin-related peptides in aqueous media using a molecularly imprinted polymer synthesized by the epitope approach. J. Chromatogr. A 2000, 889, 111-118. [CrossRef]

11. Shi, Y.; Wan, Y.; Zhao, D. Ordered mesoporous non-oxide materials. Chem. Soc. Rev. 2011, 40, 3854-3878. [CrossRef] [PubMed]

12. Taguchi, A.; Schüth, F. Ordered mesoporous materials in catalysis. Microporous Microporous Mater. 2005, 77, 1-45. [CrossRef]

13. Li, W.; Zhao, D. An overview of the synthesis of ordered mesoporous materials. Chem. Commun. 2013, 49, 943-946. [CrossRef] [PubMed]

14. Gao, Z.M.; Yang, X.Q.; Wu, N.N.; Wang, L.J.; Wang, J.M.; Guo, J.; Yin, S.W. Protein-based pickering emulsion and oil gel prepared by complexes of zein colloidal particles and stearate. J. Agric. Food Chem. 2014, 62, 2672-2678. [CrossRef] [PubMed]

15. Chen, Y.; Li, X.; Yin, D.; Li, D.; Bie, Z.; Liu, Z. Dual-template docking oriented molecular imprinting: A facile strategy for highly efficient imprinting within mesoporous materials. Chem. Commun. 2015, 51, 10929-10932. [CrossRef] [PubMed]

16. Chen, J.; Lei, S.; Xie, Y.; Wang, M.; Yang, J.; Ge, X. Fabrication of high-performance magnetic lysozyme-imprinted microsphere and its NIR-responsive controlled release property. ACS Appl. Mater. Interfaces 2015, 7, 28606-28615. [CrossRef] [PubMed]

17. Yue, Q.; Li, J.; Luo, W.; Zhang, Y.; Elzatahry, A.A.; Wang, X.; Wang, C.; Li, W.; Cheng, X.; Alghamdi, A.; et al. An interface coassembly in biliquid phase: Toward core-shell magnetic mesoporous silica microspheres with tunable pore size. J. Am. Chem. Soc. 2015, 137, 13282-13289. [CrossRef] [PubMed]

18. Hudson, S.; Cooney, J.; Magner, E. Proteins in mesoporous silicates. Angew. Chem. Int. Ed. 2008, 47, 8582-8594. [CrossRef] [PubMed]

19. Zhou, Y.; Antonietti, M. A novel tailored bimodal porous silica with well-defined inverse opal microstructure and super-microporous lamellar nanostructure. Chem. Commun. 2003, 20, 2564-2565. [CrossRef]

20. Žilková, N.; Zukal, A.; Čejka, J. Synthesis of organized mesoporous alumina templated with ionic liquids. Microporous Microporous Mater. 2006, 95, 176-179. [CrossRef]

21. Kuang, D.; Brezesinski, T.; Smarsly, B. Hierarchical porous silica materials with a trimodal pore system using surfactant templates. J. Am. Chem. Soc. 2004, 126, 10534-10535. [CrossRef] [PubMed]

22. Zhang, J.; Ma, Y.; Shi, F.; Liu, L.; Deng, Y. Room temperature ionic liquids as templates in the synthesis of mesoporous silica via a sol-gel method. Microporous Microporous Mater. 2009, 119, 97-103. [CrossRef]

23. Lofgreen, J.E.; Ozin, G.A. Controlling morphology and porosity to improve performance of molecularly imprinted sol-gel silica. Chem. Soc. Rev. 2014, 43, 911-933. [CrossRef] [PubMed] 
24. Sprynskyy, M.; Kowalkowski, T.; Tutu, H.; Cukrowska, E.M.; Buszewski, B. Ionic liquid modified diatomite as a new effective adsorbent for uranium ions removal from aqueous solution. Colloids Surf. A Physicochem. Eng. Asp. 2015, 465, 159-167. [CrossRef]

25. Shen, G.; Zhang, X.; Shen, Y.; Zhang, S.; Fang, L. One-step immobilization of antibodies for $\alpha$-1-fetoprotein immunosensor based on dialdehyde cellulose/ionic liquid composite. Anal. Biochem. 2015, 471, $38-43$. [CrossRef] [PubMed]

26. Zhang, N.; Hu, X.; Guan, P.; Du, C.; Li, J.; Qian, L.; Zhang, X.; Ding, S.; Li, B. Preparation of protein imprinted microspheres using amphiphilic ionic liquid as stabilizer and emulsifier via miniemulsion polymerization. Chem. Eng. J. 2017, 317, 356-367. [CrossRef]

27. Trewyn, B.G.; Whitman, C.M.; Lin, V.S.Y. Morphological control of room-temperature ionic liquid templated mesoporous silica nanoparticles for controlled release of antibacterial agents. Nano Lett. 2004, 4, 2139-2143. [CrossRef]

28. Hartmann, M.; Jung, D. Biocatalysis with enzymes immobilized on mesoporous hosts: The status quo and future trends. J. Mater. Chem. 2010, 20, 844-857. [CrossRef]

29. Wu, X.; Hou, M.; Ge, J. Metal-organic frameworks and inorganic nanoflowers: A type of emerging inorganic crystal nanocarrier for enzyme immobilization. Catal. Sci. Technol. 2015, 5, 5077-5085. [CrossRef]

30. Ding, S.; Hu, X.; Guan, P.; Zhang, N.; Li, J.; Gao, X.; Zhang, X.; Ding, X.; Du, C. Preparation of surface-imprinted microspheres using ionic liquids as novel cross-linker for recognizing an immunostimulating peptide. J. Mater. Sci. 2017, 52, 8027-8040. [CrossRef]

31. Du, C.; Hu, X.; Guan, P.; Gao, X.; Song, R.; Li, J.; Qian, L.; Zhang, N.; Guo, L. Preparation of surface-imprinted microspheres effectively controlled by orientated template immobilization using highly cross-linked raspberry-like microspheres for the selective recognition of an immunostimulating peptide. J. Mater. Chem. B 2016, 4, 1510-1519. [CrossRef]

32. Tominaga, Y.; Kubo, T.; Kaya, K.; Hosoya, K. Effective Recognition on the surface of a polymer prepared by molecular imprinting using ionic complex. Macromolecules 2009, 42, 2911-2915. [CrossRef]

33. Putra, E.K.; Pranowo, R.; Sunarso, J.; Indraswati, N.; Ismadji, S. Performance of activated carbon and bentonite for adsorption of amoxicillin from wastewater: Mechanisms, isotherms and kinetics. Water Res. 2009, 43, 2419-2430. [CrossRef] [PubMed]

34. Qian, L.; Sun, J.; Hou, C.; Yang, J.; Li, Y.; Lei, D.; Yang, M.; Zhang, S. Immobilization of BSA on ionic liquid functionalized magnetic $\mathrm{Fe}_{3} \mathrm{O}_{4}$ nanoparticles for use in surface imprinting strategy. Talanta 2017, 168, 174-182. [CrossRef] [PubMed]

35. Gao, X.; Hu, X.; Guan, P.; Du, C.; Ding, S.; Zhang, X.; Li, B.; Wei, X.; Song, R. Synthesis of core-shell imprinting polymers with uniform thin imprinting layer via iniferter-induced radical polymerization for the selective recognition of thymopentin in aqueous solution. RSC Adv. 2016, 6, 110019-110031. [CrossRef]

36. Tamahkar, E.; Kutsal, T.; Denizli, A. Surface imprinted bacterial cellulose nanofibers for cytochrome c purification. Process Biochem. 2015, 50, 2289-2297. [CrossRef]

37. Zhang, X.; Zhang, N.; Du, C.; Guan, P.; Gao, X.; Wang, C.; Du, Y.; Ding, S.; Hu, X. Preparation of magnetic epitope imprinted polymer microspheres using cyclodextrin-based ionic liquids as functional monomer for highly selective and effective enrichment of cytochrome c. Chem. Eng. J. 2017, 317, 988-998. [CrossRef]

38. Guo, T.; Deng, Q.; Fang, G.; Liu, C.; Huang, X.; Wang, S. Molecularly imprinted upconversion nanoparticles for highly selective and sensitive sensing of cytochrome c. Biosens. Bioelectron. 2015, 74, 498-503. [CrossRef] [PubMed]

(C) 2018 by the authors. Licensee MDPI, Basel, Switzerland. This article is an open access article distributed under the terms and conditions of the Creative Commons Attribution (CC BY) license (http:/ / creativecommons.org/licenses/by/4.0/). 